\title{
Grammaticalization of perspectivity
}

\author{
Gisela Zifonun \\ Institute for the German Language, Mannheim
}

\section{Preliminaries}

Given the subject matter of this volume, I might be expected to give a precise account of perspectivity, as far as it is petrified in grammar, as a basis for its application in discourse strategies: Unfortunately, in my opinion, the state of the art does not allow such a straightforward procedure. What I will try to do is to check the field: How can perspectivity be captured within grammar? Which concepts are needed in addition? Therefore I will not go into the connection between grammar and discourse apart from some remarks in Section 9.

\section{The concept of perspectivity: Outline and definitions}

There may be quite different aspects of perspectivity that are reflected in grammar or even grammaticalized. The deictic categories (personal, local, temporal deixis) are means for localizing persons including the speaker and hearer as well as states of affairs in a multidimensional space based primarily on a concept of distance (with respect to the speaker and the speech act). The language-specific systems of personal pronouns, of local and temporal adverbs, the tense systems reflect the inherent options, between which the speaker has to make his choice. This choice is guided by the speaker's 'perspective', i.e. the degree of nearness or distance the speaker is willing to attribute to the focussed entity within the dimension in question. For instance he or she can choose between the 'du'- and the 'Sie'-perspective in addressing the hearer in German or between preterite or 'narrative' or 'epic' present in referring to past events (cf. the contribution by Quasthoff in this volume). Even in referring to himself the speaker may avoid the standard pronoun for the first person singular and take a more distant and generalized perspective (German: man) or a 'sympathetic' perspective (German: $d u$ ); cf. the contribution 
by Bredel in this volume. I will not go into the grammaticalization of this 'deictic perspectivity' nor into any other other possible aspects but for the one that is central in my eyes: propositional perspectivity.

I would like to start with an attempt for a definition:

Propositional perspectivity is grammaticalized in a language, if (a) there are different propositional constructions containing the same 'content words' ('autosemantica') for referring to identical states of affairs and if (b) these differences can be conceived as differences in perspective.

What 'perspective' exactly means here, remains to be defined. But, with this definition, we can exclude right from the beginning those forms of propositional perspectivity we might call 'interpretive conceptualization'. Cases of interpretive conceptualization are for instance the choice between concieving a situation as an act of killing or an act of murdering or as conceptualizing a situation as an act of persuading contrasted with conceptualizing it as an act of convincing. In this case normally the perspectivity is reflected in the linguistic surface structure by the choice of crucially different content words (kill versus murder, persuade versus convince), which are by no means synonymous, though there may be meaning relations like hyponymy, guaranteeing their possible referential identity.

If the differences between the constructions can be traced back to the predicate expression constitutive for the proposition, that is, in general the verb, and if these differences are differences in the grammatical realization of the arguments of the verb, I call it 'conversion' (converses). In the following I restrict myself to such pairs or tuples of converses. With respect to these converses the definition given above counts as a hypothesis, i.e. it may be the case, that converses can be explained as cases of grammaticalization of propositional perspectivity, but it is also possible that only part of the definition applies or even that the explanation fails.

\section{Types of converses}

First of all let me give an overview to the types of converses I shall deal with.

\section{Types of converses}

\section{i. Converses with identical verbs}

A interessiert sich für $B$

(ärgern, begeistern, freuen, empören)

"A is interested in B"

(annoy, enchant, please, disgust)

A schickt dem $B$ ein $C$

"A sends B a C"
$B$ interessiert A

"* $\mathrm{B}$ interests $\mathrm{A} " 1$

A schickt ein $C$ an $B$

"A sends a $\mathrm{C}$ to $\mathrm{B}$ " 
A füllt ein $B$ in ein $C$

"A fills a B into a C"
$A$ füllt ein $C$ mit $B$

"A fills a $C$ with B"

ii. Converses with change in verb form, especially passive

A schenkt dem B ein C

"A gives $\mathrm{B}$ a $\mathrm{C}$ as a present"

\section{iii. Converses by word formation}

Prefix verbs:

A wirft ein B auf/gegen/an ein C

(laden, hängen, kleben, malen, sprühen)

"A throws a B onto/against a C"

(load, hang, glue, paint, spray)

A schenkt dem B ein C

(liefern, schicken)

"A gives $\mathrm{C}$ as a present to $\mathrm{B}$ "

(deliver, send)

A kauft von B ein $C$

"A buys a C from B"

Particle verbs (particle not separable):

$A$ baut ein $B$ um $C$

(hüllen um, ziehen über, legen unter)

"A builds a B around C"

(lay around ('cover'), pull over, lay under)

iv. Lexical converses

$A$ besitzt ein $B$

"A possesses a B"

A gibt dem $B$ ein $C$

"A gives $\mathrm{B}$ a C" ein $C$ wird dem B von A geschenkt

der $B$ bekommt ein $C$ von $A$ geschenkt

"a $C$ is given to $B$ as a present by $A$ "

" $\mathrm{B}$ is given a $\mathrm{C}$ as a present by $\mathrm{A}$ "
A bewirft ein B mit C

(beladen, behängen, bekleben, bemalen, besprühen)

"*A PREF-throws a B with C"2

A beschenkt den $B$ mit $C$

(beliefern, beschicken)

“*A PREF-gives B with C" (etc.)

$B$ verkauft dem $A$ ein $C$

"*B PREF-buys A a C"

("B sells A a C")

A umbaut $C$ mit $B$

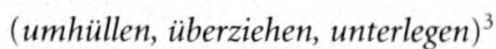

"*A around-builds $\mathrm{C}$ with $\mathrm{B}$ " (etc.)

I am not going to deal with lexical converses. This would be a matter of "lexicalization of perspectivity". Lexical converses differ from interpretive conceptualization by truth-functional equivalence (with respect to standard contexts, cf. Section 4) or even synonymy between the pairs of lexical items, though there may be borderline cases. But certainly there are close relationships between lexical and grammatical 
converses. The first three forms are cases of grammatical conversion and I shall examine the issue of perspectivity with them.

\section{Propositional identity and perspectivity: Problems}

There are some essential difficulties captured in the following three questions:

- When are two or more propositions or the states of affairs corresponding with them identical?

- When does a difference in perspective exist?

- Is truth-functional equivalence a necessary and sufficient precondition for perspectivity pairs or tuples?

The three questions are not independent of each other. With respect to discussing the first two questions there is a difference between starting with propositions or even propositional functions and starting with states of affairs. As for propositions the usual procedure is to compare two different propositions or propositional functions, as I did. The identity of propositions is only accessible by truth-functional equivalence. More exactly: two non-tautological propositions are identical iff they represent the same intensions, conceived as functions from indices to truth values in the sense of David Lewis (1970). So we could say that two propositions specifying identical functions from indices to truth values refer to the same states of affairs. Here we have no concept of state of affairs independent from the concept of linguistic proposition. I think, with this starting point, the second question, i.e. the problem of perspectivity, will typically arise in a specific form: You will notice, that the two propositional construction types come out true almost always in the same situations, but that there are some situations where they do not both come out true and where either one comes out true, one false or where one can not be successfully evaluated at all. Here we are inclined to say that the two propositions always describe (in a sense) different states of affairs, but that in some cases these differences can be neglected. In this case we accept the fundamental perspectivity of any linguistic interpretation without being forced to determine a common starting point. On the other hand, starting with states of affairs as independently given entities and coming up with their propositional descriptions the idea of a single given thing open to different linguistic interpretation is foregrounded, and here we approach the problem of perspectivity in a different manner: In this case we are inclined to accept the two different propositional constructions as descriptions of the same states of affairs and ascribe their difference to different interpreting points of view. So the two different starting points lead to two different concepts of propositional perspectivity: 
- fundamental perspectivity (starting with propositions)

- secondary perspectivity (starting with states of affairs).

I suppose that this divergence, which has up to now not sufficiently been cleared, plays an important role in the problem at hand. I am not able myself to fix my position definitely, but I hope, the two positions can be recognized in the following.

With respect to the third question one thing seems to be quite clear: The judgements about truth-functional equivalence between for example constructions with kaufen - verkaufen diverge in general. And certainly converses are not interchangeable in all contexts under the same truth conditions. So where we might accept

(1) A verkauft C ein B für D / A verkauft ein $B$ an $C$ für $D$ "A sells C a B for D" / "A sells a B to C for D"

as a reasonable statement, we might not always be willing to accept its converse

(2) C kauft ein B von A für D

"C buys a B from A for D"

as a reasonable statement and vice versa.

If for instance a car seller tells his reluctant client: "Ich verkaufe Ihnen jedes Modell"/"I sell you any model", it does not follow that the client will buy every model nor that he will buy any model at all. That is, the equivalence only holds in certain standard contexts, i.e. in descriptive contexts, where the corresponding state of affairs is being factually realized and not only intended or considered as possible ("intensional contexts"). Generic sentences may be another type of context where kaufen - verkaufen cannot be considered equivalent: Schmidt verkauft Kühlschränke an Isländer / Smith sells refrigerators to Icelanders versus Isländer kaufen Kühlschränke von Schmidt / Icelanders buy refrigerators from Smith.

\section{Propositional identity and perspectivity: Positions}

Considering only such standard contexts (see preceding section) there are the following possibilities for dealing with propositional identity between pairs or tuples of converses. It seems to be convenient to start with the - more usual-approaches, corresponding to secondary perspectivity before proceeding to the approach associated with fundamental perspectivity. (I also make use of the concept of 'semantic role', which will be dealt with later, in a preparatory manner):

a. We assume that there is no difference in truth conditions (starting point preferably: state of affairs), then either 1,2 or 3 : 
1. The different grammatical packing is semantically completely irrelevant. A thing like difference in grammatical perspective does not exist. Semantic roles are not to be assumed or it is assumed that identical truth conditions imply identical semantic roles.

2. The different grammatical packing is pragmatically relevant. It has got to do with differences in foregrounding/backgrounding.

3. The different grammatical packing is semantically/pragmatically relevant. It has got to do with different semantic roles. Identical truth conditions do not imply identical semantic roles.

b. We assume that there may be (not necessarily is) a difference in truth conditions (starting point preferably: tuples of propositions), then either 1 or 2 :

1. The difference can be handled without different semantic roles by a more exact semantic description.

2. Roles have an influence on truth-functional semantics. Different roles may imply different truth conditions.

The whole issue is sometimes being complicated by the fact that some authors argue for position (a), some for (b) with respect to the same pair of converses. So with respect to pairs like German sprühen auf, besprühen mit, English spray onto spray with many people assume a truth-functional difference: besprühen/spray with is said to imply an additional condition of completiveness or perfectivity. Jackendoff (1991) for instance however doubts such a principled difference (see also Section 8.1).

In the following I will neglect some further problems of conversion: the problem of difference in facultative arguments (for instance between kaufen, verkaufen, kosten, "buy", "sell", "cost"), the problem of loss of one argument (Hans zerbricht das Fenster - Das Fenster zerbricht, Hans öffnet die Tür - die Tür öffnet sich, "Hans is breaking the window" - "The window is breaking" "Hans opens the door" - The door is opening"). Even this can be considered as a question of perspectivity.

The positions concerning propositional identity of converses mentioned above can serve as a basis for deriving different concepts of perspectivity. We have the following alternatives corresponding to the positions in (a) and (b):

I. Derived from (a2): Perspectivity refers to an aspect based on backgroundingforegrounding or centrality-periphery: Perspectivity is foregrounding and backgrounding.

II. Derived from (a3): Perspectivity refers to different conceptualization of identical states of affairs, involving different roles: Perspectivity is 'secondary perspectivity' with role shift. 
III. Derived from (a2) + (a3): Perspectivity refers to different conceptualization of identical states of affairs, involving shift in backgrounding/foregrounding and at the same time different semantic roles: Perspectivity is 'secondary perspectivity' with role shift and shift in backgrounding/foregrounding.

IV. Derived from (b2): Perspectivity cannot be suspended at all. Cognition and conceptualization are always forms of perspectivity, roles intrinsically have perspective, a hidden identical "state of affairs" is not to be assumed: Perspectivity is 'fundamental perspectivity'.

As you see, I did not mention two positions any longer: (al) excludes any concept of perspectivity and (b1) does not supply us with any practical concept for dealing with perspectivity. So in the following I concentrate on the positions involving two practical preparatory concepts of grammatical perspectivity, i.e. the concept of semantic role and the concept of foregrounding or centrality.

\section{Concepts for semantic roles}

Now, how are roles to be understood? I will not discuss the whole range of problems connected with semantic or 'thematic' roles (cf. for example Dowty 1989). The intuitions behind the concept are: (1) There are systematic, non-arbitrary correlations between the participants of states of affairs (i.e. events, processes and states) and the syntactic complements expressing those participants. (2) These correlations can be (partly) explained by generalizing the two-place relations between the state of affairs and the individual participant. (Note, that so far it does not matter which one of the two starting points, proposition or state of affairs, is chosen.) So we might accept the definition in Kamp and Roßdeutscher (1994:101): "Thematic roles are functions from eventualities (i.e. events, processes or states) to entities that are implicated (in one way or another) in those eventualities". Again the different concepts of semantic roles can be associated with the alternatives (ai) versus (bi) from Section 5:

Concept 1 based on (a1): denotative concept of semantic role

Concept 2 based on (a3): designative concept of semantic role, assuming in addition a possible denotative identity

Concept 3 based on (b2): designative concept of semantic role without assuming denotative identity.

Fillmore (1968) supported a concept of denotative semantic roles (Concept 1): A state of affairs is captured in one and only one canonical form involving a certain constant configuration of semantic roles like AGENT, PATIENT, EXPERIENCER. These remain invariable throughout all the different syntactic representations of a 
"scene" for instance by converse verbs like the ones mentioned above. Perspectivity can only play a role insofar as certain participants may be selected from the whole set of participants and insofar as perhaps one or the other is being foregrounded.

In contrast Helbig pleads in several articles (cf. especially Helbig 1992) for a designative concept of semantic role (Concept 2). Designative roles may reflect different aspects of participation for identical participants in a single scene: The participant who sells a book is identical to the one from whom the book is bought; but as a seller he plays a role different from the role he plays as the man who is bought from. A designative concept presupposes a non-arbitrary relation between surface cases and semantic roles. Whereas Fillmore seems to assume such an arbitrary relationship, in this conception a rule-guided relation between surface cases and semantic roles is argued for. In this connection one idea was extremely influential: the idea of a hierarchy of semantic roles that is connected with - not in a one-to-one mapping, but in a rule-guided manner - a hierarchy of syntactic cases. There are different proposals for such an hierarchy (Dik 1981; Givon 1984; Primus 1995), see also in the Government and Binding framework the concept of 'linking' (e.g. Wunderlich 1997).

\section{Hierarchy of semantic roles and syntactic mapping in GDS}

\subsection{Hierarchy of roles}

I will give here a simplified version of the hierarchy presented in the "Grammatik der Deutschen Sprache" (GDS, Zifonun et al.: 1326), which has been influenced especially by Plank (1979). In general the concept of 'designative semantic role' is adopted

$$
\begin{aligned}
& \text { AG } \\
& \text { CAUS }
\end{aligned}>\begin{aligned}
& \text { REC } \\
& \text { POSS } \\
& \text { EXP }
\end{aligned}>\begin{aligned}
& \text { OBJ } \\
& {[\text { THEME }]}
\end{aligned} \mid>\text { CO-AG }>\text { THEME }>\begin{aligned}
& \text { ORN } \\
& \text { LOC } \\
& \text { INSTR }
\end{aligned}
$$

AG: 'agent', CAUS: 'causer', REC: 'recipient', POSS: 'possessor', EXP: 'experiencer', $\mathrm{OBJ}$ : 'involved entity, entity undergoing changes (in place, substance or consistency)', THEME: 'abstract entity dealt with' (sub-role of generalized OBJ), CO-AG: 'co-agent, person acting in an event together with an agent', ORN: 'ornative, object/substance as a means for changing OBJ', LOC: 'locative', INSTR: 'Instrument'. LOC can be divided into the sub-roles GOAL, SOURCE and PATH.

Role hierarchy in GDS reflects salience order: The leftmost role, the role preceding all other roles in hierarchy, is the most salient role, along the dimensions 'activity' und 'animateness'. For the current introductory purpose it is assumed, that AG shares its primary hierarchical position with CAUS, which is equal to AG 
with respect to 'activity'. The three roles of the set 'animate' next to AG in hierarchy (constituting an equivalence class) are salient along the dimension of 'animateness', whereas OBJ/THEME are only salient with respect to 'involvement'.

There is now the hypothesis that only the roles before the vertical line can be expressed in German by a case form, whereas the ones after the line can't. Note, that THEME can show up before and after the line. We assume for instance, that Sie sprachen über seine Probleme ("They talked about his problems") as well as Sie besprachen seine Probleme (“`They PREF-talked his problems") involve a THEME. The difference between the two realizations is not fully understood yet and by now not attributed to a role difference. The general division between two sets of roles (with the just mentioned exception) implies that e.g. sentences like $\mathrm{Er} \mathrm{lädt} \mathrm{Heu}$ auf den Wagen ("He loads hay on the truck") and Er belädt den Wagen mit Heu ("He loads the truck with hay") receive different role configurations, since e. g. der Wagen as accusative object may not receive a locative role. The correlation for the subject and objects according to the GDS are:

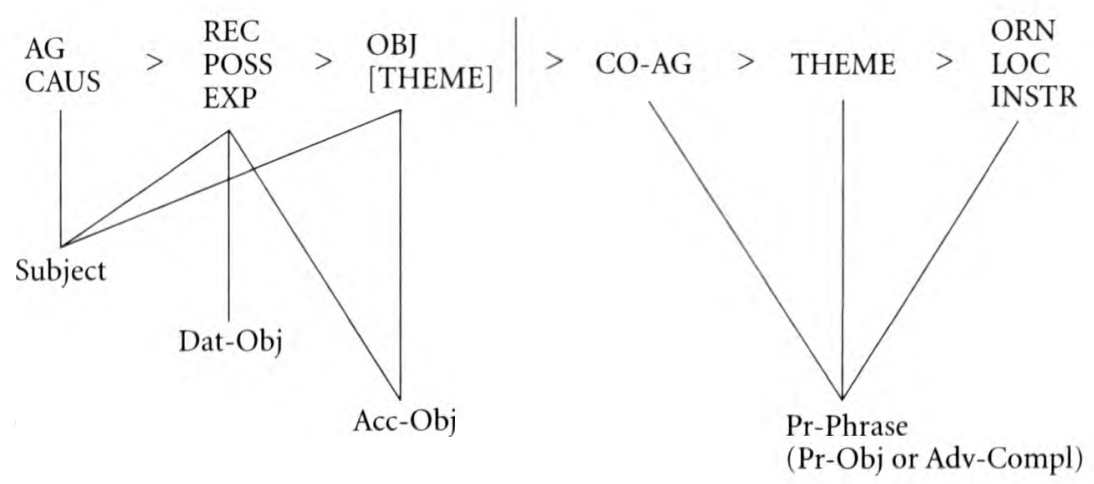

\subsection{Patterns of conceptualization}

We can now sketch the patterns of conceptualization for the pairs of converses presented above. As you will notice, names have been given to the patterns reflecting in short the difference in perspectivity going back to different configurations of roles.

\section{Pattern 1. ATTENTION-STIMULATION}

ATTENTION: Hans interessiert sich für das Buch Hans-NOM interest-3SG.PRES he-REFL.ACC for the-ACC book-ACC "Hans is interested in the book" 


STIMULATION: Das Buch interessiert Hans
The-NOM book-NOM interest-3sG.PRES Hans-ACC
"^The book interests Hans"

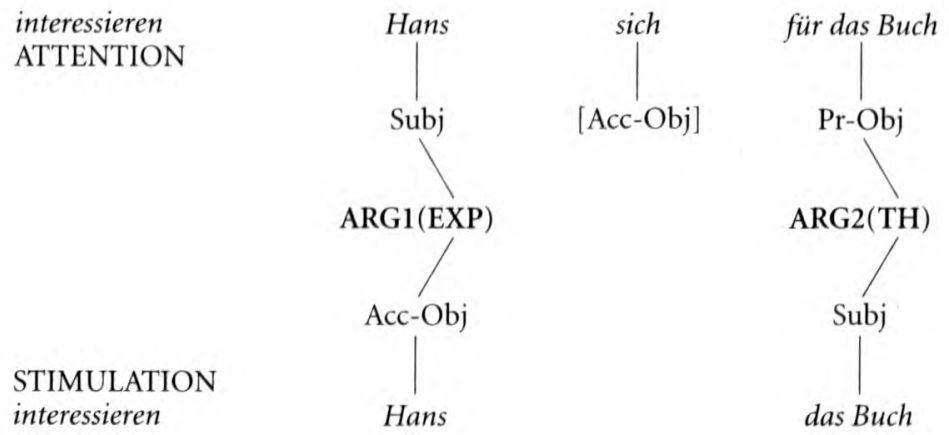

This double patterning is characteristic for a lot of German verbs denoting mental and emotional attitudes like jemand freut sich über etwas - etwas freut jemanden ("be glad about" - "make glad"), jemand ärgert sich über etwas - etwas ärgert jemanden ("to be annoyed by" - "annoy"), ich begeistere mich für etwas - etwas begeistert mich ("to be enchanted" - "enchant") and so on. As you will have noticed, in English there exist also two different patternings, but the grammatical constructions differ from the German ones: Whereas in German you have two active, process-denoting constructions, in English an active, process-denoting impersonal construction (not possible with all verbs) is contrasted with a resultative state-denoting personal construction. In German this last option can be realized in addition (ich bin erfreut über, ich bin verärgert über, ich bin begeistert von). Taking the cross-linguistic perspective of European languages, it can be shown that this double or even threefold variation in conceptualizing mental attitude is widespread and seems to mirror two principally different strategies: By choosing the first pattern (ATTENTION) mental attitudes are seen as controlled activities of the experiencer directed to their emotional contents ('themes'). By the second pattern mental attitudes are conceived as stimulated, provoked from within a more passive experiencer by the emotional stimulus. This difference is not reflected by a corresponding role difference in this approach. One alternative would have been to interpret STIMULATION as a subtype of CAUSATION and to ascribe the role CAUS to the impersonal subject phrase (das Buch). STIMULATION would be conceived as an internal causal process doing its work in the mind of the experiencer. We did not choose this solution for the following reason: Although constructions with lexical causatives in German normally allow for passivation transforming the object of the active sentence to the subject of the passive sentence, this is not, or only marginally acceptable in this case: 
(3) ${ }^{*}$ Ich werde von dem Buch /durch das

I-NOM get-1SG.PRES by the-DAT book-DAT/through the-ACC

Buch begeistert /interessiert.

book-ACC enchant-PARTII /interest-PARTII

"I am enchanted/interested by the book/through the book".

In this case, the difference in perspective remains beyond the threshold of differenciated role concepts.

Pattern 2. TRANSACTION-TRANSFER

$\begin{array}{llll}\text { TRANSACTION: } & \text { Hans schickt } & \text { Eva ein Buch } \\ & \text { Hans-Nom send-3sg.PRES } & \text { Eva-DAT a-ACC book-ACC } \\ & \text { "Hans sends Eva a book" } & & \end{array}$

TRANSFER: Hans schickt ein Buch an Eva Hans-Nom send-3sG.Pres a-ACC book-ACC to Eva-ACC "Hans sends a book to Eva"

schicken

TRANSACTION

TRANSFER

schicken

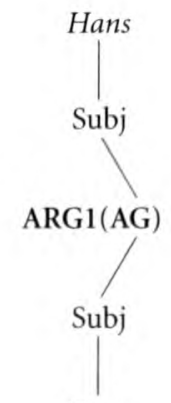

Hans

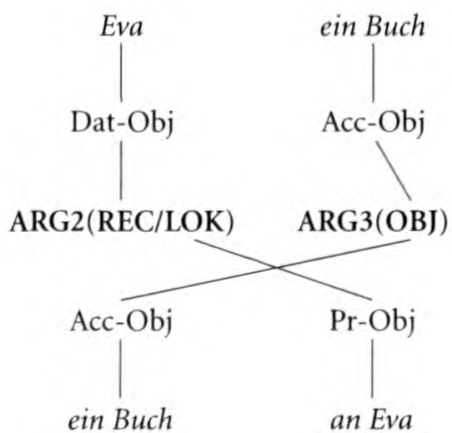

In this case the double patterning indeed involves role shift for the second argument (ARG2). In the pattern of TRANSACTION the second argument figures as recipient, whereas it figures as locative goal in the pattern of TRANSFER. The pattern of TRANSACTION is restricted to personal arguments (natural persons or institutions), the locative goal of the pattern of Transfer is unrestricted: Hans schickt ein Buch nach Frankfurt - ${ }^{*}$ Hans schickt Frankfurt ein Buch ("Hans sends a book to Frankfurt" - *Hans sends Frankfurt a book"). The dative object representing ARG2 in recipient role can be promoted to subject in passive voice (so called bekommenPassiv): Eva bekommt ein Buch geschickt ("Eva is sent a book"), prepositional objects are excluded from promotion. In English we observe the corresponding phenomenon of 'dative alternation/shift'. For the German and the corresponding En- 
glish converses there exists a slight semantic difference between the elements of the pair, which can be made explicit in the following elaborations:

(4) a. Hans schickte das Buch an Eva, aber sie hat es nicht erhalten. "Hans sent the book to Mary, but she didn't get it"

b. ${ }^{\star}$ Hans schickte Eva das Buch, aber sie hat es nicht erhalten. "Hans sent Mary the book, but she didn't get it"

(cf. Czepluch 1997:6)

This difference supports the role shift between REC and LOC and could in addition be taken as one piece of argument in favour of the narrower concept of 'designative roles', where no denotative identity is to be assumed (Concept 3 from Chapter 6). In this case, however, there is an implicational relationship between the two patterns. Or more exactly:

(Implication 1): Whenever in a situation $s_{\mathrm{i}}$ a proposition of the pattern of TRANSACTION holds, then also the corresponding pattern of TRANSFER holds (provided that the predicate expression of the proposition provides for this conversion), but not vice versa. ${ }^{4}$

Pattern 3. TRANSFER-AFFECTEDNESS

TRANSFER: Hans füllt Wein in die Flasche Hans-NOM fill-3sG.PRES wine-ACC into the-ACC bottle-ACC "Hans fills wine into the bottle"

AFFECTEDNESS: Hans füllt die Flasche mit Hans-NOM fill-3sG.PRES the-ACC bottle-ACC with Wein wine-DAT

"Hans fills the bottle with wine"

füllen

TRANSFER

AFFECTEDNESS füllen

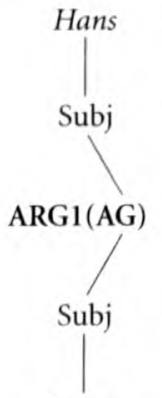

Hans

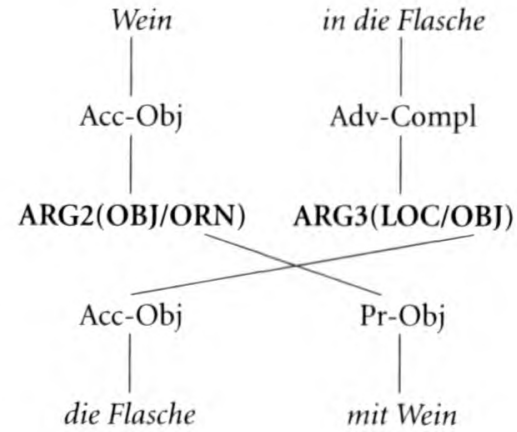


In this case, there is a double role shift. The locative argument (ARG3) of the pattern of TRANSFER adopts the OBJ-role in the pattern of AFFECTEDNESS, whereas the OBJ-argument (ARG2) of TRANSFER becomes ORN in the pattern of AFFECTEDNESS. The exchange in the role of strongly involved participant $(=\mathrm{OBJ})$ and the loss of a locative role seems to be quite a dramatic change often characterized as an additional 'holistic' component concerning the OBJ argument of the pattern of AFFECTEDNESS. Again we may capture this component by an elaboration:

(5) a. Hans füllte Wein in die Flasche, aber sie wurde nicht ganz voll. "Hans filled wine into the bottle, but it didn't get quite full"

b. ${ }^{*}$ Hans füllte die Flasche mit Wein, aber sie wurde nicht ganz voll. "*Hans filled the bottle with wine, but it didn't get quite full"

Again there is an implicational relationship between the two patterns, quite analogue to the first one:

(Implication 2): Whenever in a situation $s_{\mathrm{i}}$ a proposition of the pattern of AFFECTEDNESS holds, then also the corresponding pattern of TRANSFER holds (provided that the predicate expression of the proposition provides for this conversion), but not vice versa.

Generalizing over the two patterns considered by now we may conclude that the locative pattern of TRANSFER makes a somewhat "weaker" claim than the the associated patterns of TRANSACTION or AFFECTEDNESS. Note, that in this framework the relationship between the patterns is not interpreted as some sort of 'meaning inclusion', but as two independent meanings interrelated only by implications (meaning postulates).

We get a similar picture with some pairs of converses in word formation: laden ("load"), hängen ("hang"), kleben ("glue"), malen ("paint"), bauen um ("build around"), hüllen um ("lay around"), ziehen über ("pull over"), legen unter ("lay under") (TRANSFER), beladen, behängen, bekleben, bemalen, umbauen, umhüllen, überziehen, unterlegen (AFFECTEDNESS). In the case of jemandem etwas liefern etwas liefern an jemanden - jemanden mit etwas beliefern ("deliver") we even have three patterns: TRANSACTION; TRANSFER; AFFECTEDNESS.

Verb pairs like kaufen - verkaufen ("buy" - "sell") or erben - vererben ("inherite" - "leave as a heritage") seem to be more isolated within German word formation, but there are also instances of this pattern of RECEPTION-TRANSACTION with lexical conversion as geben - bekommen/erhalten ("give" - "receive") or English buy - sell. 
Pattern 4. RECEPTION-TRANSACTION

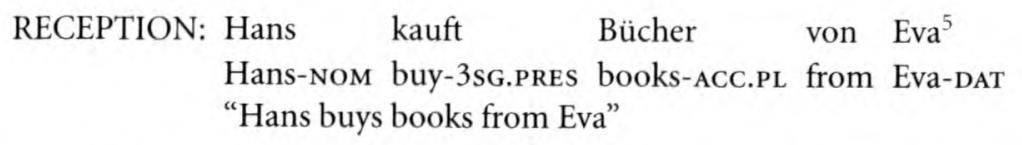

TRANSACTION: Eva verkauft Hans Bücher

Eva-Nom sell-3sG.PRES Hans-DAT books-ACC.PL

"Eva sells Hans books"

kaufen

RECEPTION

TRANSACTION

verkaufen

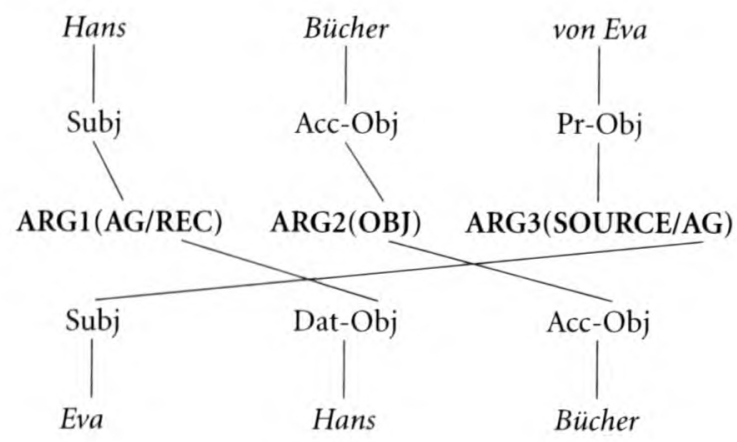

As in the cases mentioned above also a pattern of TRANSFER can be realized with the transaction verb: verkaufen an, vererben an ("sell to", "leave").

In the case of active and passive, at the first sight there are no obvious role differences between the converses. But notice that in the GDS framework the vonphrase ist not to be regarded as a syntactic complement of the verb. If it were a syntactic complement, the AGENT-phrase necessarily would be represented as subject. You rememember AGENT is the semantic role with the highest rank corresponding to the syntactic case with the highest rank, the nominative of the subject. So I assume here that the pattern of ACTION (active voice) is associated with a pattern of corresponding PROCESS, where a "degraded agent" is supposed to be involved but need not be mentioned. This degradation is indicated by the broken line in the pattern representation; it means that the passive prepositional phrase is (most likely) to be regarded as an adjunct, not as a complement. Again as with pattern 1 one might assume a role difference, but again I shall leave the case open.

Pattern 5. ACTION-PROCESS (DEGRADING OF AGENT)

ACTION: Eva schenkt Hans das Auto

Eva-Nom give-3sg.pres Hans-DAT the-ACC car-ACC

"Eva gives Hans a car as a present" 


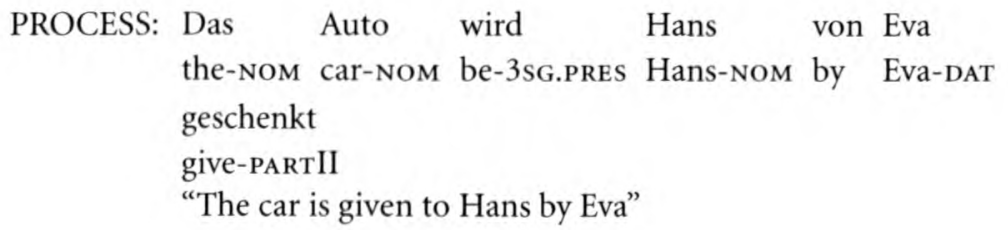

schenken

ACTIVE

PASSIVE

geschenkt werden

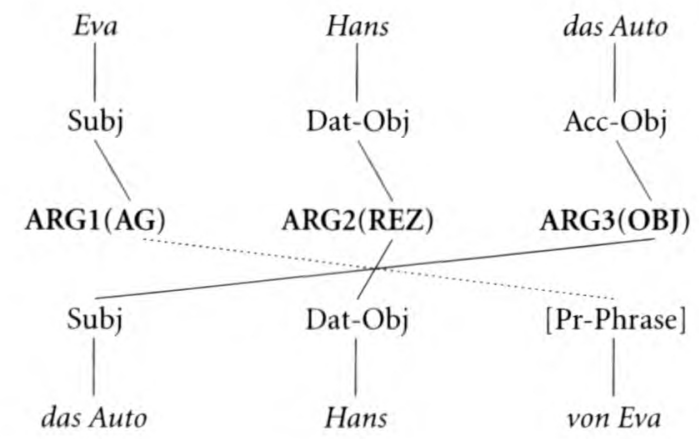

In summary, my approach can be identified as Type IV, derived from (b2): Converse pairs are represented by pairs of patterns that assign (in most cases) different (designative) participant roles to some arguments out of the whole set of identical arguments of the corresponding patterns. Denotative identity is not explicitely assumed and not reflected in the representation.

\section{Two-level approaches: Denotative and designative level}

You might say, that Approach II derived form (a3) seems more interesting and more adequate. And indeed, there are two approaches in the spirit of (IIa3), apparently independent of each other: the approaches of Jackendoff 1991 and Ickler 1990. ${ }^{6}$ Both assume a two-level approach. On the first level they represent a state of affairs only by roles involving concepts like Theme, Place, Path, Goal (Jackendoff) or statische Entität ("static entity"), dynamische Entität ("dynamic entity"), verursachende Entität ("causing entity") (Ickler). This level is called the "thematic tier" in Jackendoff 1991, and the level of "roles neutral in perspective" in Ickler. Only on a second level, the "action tier" or the level of "perspective roles" like Actor; Patient; Beneficiary (Jackendoff), "effected entity"; "affected entity", "ornative entity" (Ickler) is introduced. 


\subsection{Jackendoff}

With the help of this two level approach in Jackendoff 1991 typical converse pairs like ours obtain a common representation on the first level (reflecting their denotative identity) and differ in representation on the second level. So Jackendoff comments pairs like Bill loads books on the truck - Bill loads the truck with books, Bill smears paint on the wall - Bill smears the wall with paint with the following words: "The thematic relations in each case are the same: the books go onto the truck, the paint goes onto the wall. The change is in which entity is viewed as most directly "affected" by Bill's action and the direct object has a stronger claim on the role in either case. Thus the action tier is strongly implicated in choice of objects as well as subjects" (Jackendoff 1991:130). The corresponding representations are (in a simplified version):

common representation on thematic tier for load on - load with (see Pattern 3)

[CAUSE([BILL], [INCH [BE ([HAY]; [ON [TRUCK]])]])]

"Bill causes that hay starts to be on the truck"

action tier for load on:

[AFF ([BILL], [HAY])]

action tier for load with:

[AFF ([BILL], [TRUCK])]

The first denotative level ("thematic tier") is 'localistic'. Events are on this fundamental level events of motion or stativity or events of causing those events of motion or stativity. This localistic view comprehends not only the field of spatial location and motion, but also possession (covering the concepts of 'have', 'possess', 'sell', buy' and so on), ascription of properties (concepts like 'be + adjective') or scheduling of activities (concepts like 'take place', 'change/keep'). There is, by the way, not only in the approach of Jackendoff, going back to Gruber 1965, a general tendency to reconstruct conceptual or semantic categorization in quite a mechanistic model.

Let us return to the question of semantic roles: In Jackendoff's representations no role names show up. Theme, Agent and so on are not primitives of the semantic theory, but "particular structural configurations in conceptual structure" (Jackendoff 1991:47). So, in our example, Bill is Agent, because Agent is is the first argument of the Event-function CAUSE (ibid.), ${ }^{7}$ hay is Theme, because it is the first argument of the State-function BE, truck is Goal, because it is the argument of $\mathrm{ON}$ in a configuration, where $\mathrm{ON}$ is embedded within INCH and INCH embedded in CAUSE. This approach to semantic roles seems to be quite promising since it avoids role concepts as unmotivated labels - provided that the language of 
conceptual representation itself has a clear cut design and can be interpreted along the established rules of (for instance) model theoretic interpretation. I leave this question open for the language Jackendoff adopts.

What about the the second level, the "action tier"? Again role concepts are "hidden" in the structural framework: The first argument of the function AFF ("affect") is the Actor, the second is the Patient. There is no one-to-one-mapping between the roles of the two tiers. In our Pattern 3 the Agent of the thematic tier corresponds to Actor on the action tier and either Theme or Goal of the thematic tier can be represented as Patient (yielding the different 'designative' interpretation). But there are also different correspondences.

Look for example at Jackendoff's solution for my Pattern 2:

common representation on thematic tier for give (double object) - give to (see Pattern 2):

$\left[\right.$ CAUSE $\left([\right.$ BILL $],\left[\right.$ GO $_{\text {Poss }}\left([\mathrm{BOOK}],\left[\begin{array}{l}\text { FROM }[\text { HARRY }]])])] \\ \text { TO }[\text { SAM }]\end{array}\right]\right.$
"Bill causes that a book goes-in-possession from Harry to Sam"

action tier for give (double object):

$\left[\mathrm{AFF}^{+}([\mathrm{BILL}],[\mathrm{SAM}])\right]$

action tier for give to:

[AFF ([BILL], [BOOK])]

Here the Theme only in give NP to NP is considered as "some sort of quasi-Patient" (Jackendoff 1991:136), whereas in the double object construction the personal object is interpreted as Beneficiary (first argument of $\mathrm{AFF}^{+}$) (ibid.: 135).

I'll not present his solution for "psych-verbs" (see Pattern 1) in detail. Jackendoff tries here to extend his approach of "force-dynamics" also to converse pairs like please-like (lexical converses, roughly corresponding to Pattern 1), associating with them patterns of 'positive Affection' and 'positive Reaction' correspondingly (cf. ibid.: 141).

\subsection{Ickler}

Ickler does not decompose the verbs in primitive semantic predicates. In this respect the approach is nearer to the GDS approach; indeed the GDS description has partly been influenced by Ickler. Ickler also does not present a full description in terms of semantic roles. But we may contrast in the spirit of her analysis the German version of Jackendoff's load on-load with alternation (Pattern 3) (Ickler 1990: 15): 


\section{DYN./CENTRAL STAT./PERIPHERAL \\ Hans lädt Heu aufden Wagen \\ STAT./CENTRAL DYN./PERIPHERAL \\ Hans belädt den Wagen mit $\mathrm{Heu}$}

As in Jackendoff's approach, the underlying level, representing the state of affairs "neutral in perspective", is localistic in a way. $\mathrm{Heu}$ ("hay") denotes in both patterns the entity being moved, the "dynamic entity", Wagen ("truck") denotes in both patterns the "static entity", the entity not being moved. Change in perspectivity depends on whether the dynamic or the static entity is in the focus of the speaker's interest. The pattern where the dynamic entity is in the focus (f) is called "existence perspective" with respect to $f$, the pattern where the static entity is in the focus $f$ is called "characterizing perspective" with respect to $f$. As you can see, Ickler connects the question of perspectivity not only with the concept of denotative and designative role but also with the notion of centrality or periphericity, i.e. with the concept of foregrounding/backgrounding. That is, in the approach of Ickler (not so apparent in the approach of Jackendoff) we have position (IIIa2) + (a3): As in the GDS Ickler starts with a concept of syntactic-morphological centrality (only pertinent to subject and accusative object). But she joins to this syntactic concept the idea of a centrality with respect to the interest of speaker/hearer. Subject and direct object, she says, are being mentioned for their own sake, not in order to characterize other participants.

In my opinion this pragmatic concept of centrality is to be kept apart from a concept of semantic centrality - hidden in the GDS and Jackendoff approach. Pragmatically central participants are central with respect to the speaker (and are supposed to be equally central from the viewpoint of the hearer): those entities the speaker is dealing with for their own sake. Semantically central entities are those central with respect to the eventuality: those entities that are most prominent (active, involved) in the scene. ${ }^{8}$ Now distinguishing those two concepts on theoretical grounds does not mean that we could decisively say which of them is 'really' involved in our case. Perhaps further investigation will show that indeed both are needed.

\section{Propositional perspectivity and discourse}

The indeterminateness concerning semantic and pragmatic centrality however is not to be transferred to the level of utterance and connected discourse. The (semantic/pragmatic) centrality of participants in patterns of conceptualization is not to be confused with actual topic-comment-structure nor with actual focus strucure (see also the contribution by von Stutterheim and Klein in this volume). Those 
structures in actual discourse are expressed by means of word ordering and intonation. Thus conceptual centrality is connected with the level of utterance and discourse only in an indirect way. Paradoxically, the central entities of conceptualization usually tend to stay in the background of actual utterances: The subject most typically figures as topic, i.e. it represents the already known background, starting point for important, foregrounded information. It also tends to be placed in the first part of the utterance or even as the first constituent, whereas the informational focus of the utterance tends to be in the second part of the utterance. At the same time, as we have seen, the subject belongs (together with the direct object) to the conceptual centre of the corresponding pattern. Thus when we are interested in perspectivity of discourse we have to take into account one general correlation: What is to be the informational centre or focus in an ungoing discourse, should not be central in the sense of grammaticalized perspectivity. Look at the following short part from a story by Bert Brecht:

(1) Herr Keuner dachte, die Reichen seien schlechte Leute, aber seine Freundin dachte, sie seien nicht schlecht. (2) Warum dachte sie, die Reichen seien nicht alle schlecht? (3) Sie dachte es nicht, weil sie Geschenke von ihnen annahm, denn sie glaubte von sich selber, sie würde keine Geschenke von schlechten Leuten annehmen.

(B. Brecht, Prosa Bd. 2 (Geschichten von Herrn Keuner): 402)

"(1) Herr Keuner thought, the rich were bad people, but his friend thought they weren't bad. (2) Why did she think, the rich were not all bad? (3) She didn't think so, because she accepted presents from them, and she believed of herself that she wouldn't accept presents form bad people."

In sentence (3) sie refers to Keuner's friend who had been introduced in sentence (1) and is to be considered a a topic both in sentence (2) and (3). So sie represents background information for the ongoing narration, which is focussed on the new information about the presents she receives. In the embedded sentence weil sie Geschenke annahm (part of (3)) sie is subject in the role of RECIPIENT and is semantically/pragmatically central in a pattern of RECEPTION. So this is a typical case of non-coincidence between conceptual foreground and discourse focus. This kind of a balancy between conceptual centrality and discourse or informational centrality is up to further investigation.

\section{Conclusion}

There are different approaches to grammaticalization of propositional perspectivity, reaching from a concept of fundamental perspectivity in conceiving eventual- 
ities (GDS approach with designative semantic roles), over concepts of secondary perspectivity (involving both a concept of denotative and designative semantic role, approach of Jackendoff) to approaches with secondary perspectivity and foregrounding/backgrounding (approach of Ickler). The only common ground of these approaches is the insight that natural languages apparently make use of alternative patterns of conceptualization. Therefore there must be a surplus in doing so that can be ascribed to the speaker's perspective in the very broad sense of Section 2: The alternative patterns reflect different degrees of nearness and distance that the speaker may attribute to the participants of the eventuality within a dimension of participation and/or speaker's interest.

\section{Notes}

1. Some of the converses are acceptable in English, e.g. "A is pleased with B" - "B pleases A".

2. Conversion is in some cases realized by simple verbs in English: "A loads B on C" - " $\mathrm{C}$ is loaded with B by A".

3. With particle verbs the converse relation often holds only for certain complements: $A$ zieht ein Laken über das Bett - A überzieht das Bett mit einem Laken. are converses. But: A zieht einen Pullover über den Kopf-A überzieht den Kopf mit einem Pullover are not converses.

4. Note that Czepluch ibid.,. explains the difference not by role shift but by two different verb meanings.

5. There is a facultative additional prepositional phrase denoting the amount of money being exchanged (e. g. für $50 \mathrm{DM}$, "for fifty marks") whose status as a verb complement may be debated and which is neglected here.

6. There are lots of approaches dealing with verb patterns in English and German, especially from the context of Case Grammar or Generative Grammar. But I restrict myself to these two approaches, since my interest here is quite a general one so that the manyfold differences in detail, coming up in these approaches, are not that important.

7. There is, for me, an ambiguity concerning roles: Are roles roles of world entities (like Bill) or roles of linguistic entities (like Bill). Jackendoff seems to choose the first alternative. But surely Bill (or more precisely: BILL) is the first argument of CAUSE.

8. Cf. also Langacker's Cognitive Grammar (1982/1987) where subject, and in second order direct object represent a kind of cognitive foreground in conceptualizing a scene: they are the most active ore most intensively involved participants - independent from their individual roles. 


\section{References}

Bach, Emmon, \& Robert T. Harms (Eds.). (1968). Universals in Linguistic Theory. New York: Holt, Rinehart and Winston.

Chierchia, Gennaro, Barbara H. Partee, \& Raymond Turner (Eds.). (1989). Properties, Types and Meaning. Vol. II: Semantic Issues. Dordrecht: Kluwer.

Czepluch, Hartmut (1997). An der Lexikon-Syntax-Schnittstelle: Einige Besonderheiten des englischen Verbs forgive. To appear in: Eschenlohr, Stefanie \& Franz Beckmann (Eds.), Aspekte der Diathesenforschung.

Dik, Simon C. (1981). Functional Grammar. Dordrecht: Foris.

Dowty, David R. (1989). On the Semantic Content of the Notion 'Thematic Role'. In Chierchia, Gennaro, Barbara H. Partee \& Raymond Turner (Eds.), (1989) (pp. 69-129).

Fillmore, Charles J. (1968). The Case for Case. In Bach, Emmon \& Robert T. Harms (Eds.), (1968) (pp. 1-88).

Givón, Talmy S. (1984). Syntax. A Functional-Typological Introduction. Vol. I. Amsterdam: Benjamins.

Gruber, Jerry S. (1965). Studies in Lexical Relations. Ph.D. Dissertation, MIT.

Helbig, Gerhard (1992). Probleme der Valenz- und Kasustheorie. Tübingen: Niemeyer.

Ickler, Irene (1990). Kasusrahmen und Perspektive: Zur Kodierung von semantischen Rollen. Deutsche Sprache, 18, 1-37.

Jackendoff, Ray (1991). Semantic Structures (2nd ed.). Cambridge, MA: MIT Press.

Jacobs, Joachim, Arnim von Stechow, Wolfgang Sternefeld, \& Theodor Vennemann (Eds.). (1995). Syntax. An International Handbook of Contemporary Research. Vol. 2. Berlin: de Gruyter.

Kamp, Hans, \& Antje Roßdeutscher (1994). Remarks on lexical structure and DRS construction. Theoretical Lingustics 20, 2(3), 97-164.

Langacker, Roland W. (1987). Foundations of Cognitive Grammar. Stanford: University Press.

Langacker, Ronald W. (1982). Space Grammar, Analysability, and the English Passive. Language, 58, 22-80.

Lewis, David K. (1970). General Semantics. Synthese, 22, 18-67.

Plank, Frans (1979). Ergativity, Syntactic Typology, and Universal Grammar: Some Past and Present Viewpoints. In Plank, Frans (Ed.), (1979) (pp. 3-36).

Plank, Frans (Ed.). (1979). Ergativity. Towards A Theory of Grammatical Relations. London: Academic Press.

Primus, Beatrice (1995). Relational Typology. In J. Jacobs, A. von Stechow, W. Sternefeld, \& Th. Vennemann (Eds.), (pp. 1076-1109).

Wunderlich, Dieter (1997). Cause and the Structure of Verbs. Linguistic Inquiry, 28(1), $27-68$.

Zifonun, Gisela, Ludger Hoffmann, Bruno Strecker et al. (1997). Grammatik der Deutschen Sprache. 3 Bde. Berlin: de Gruyter. 